\title{
A Study of Persian Translations of English Phrasal Verbs in Harry Potter and the Order of the Phoenix
}

\author{
Nahid Yarahmadzehi ${ }^{1}$, Ali Beikian ${ }^{1} \&$ Freshteh Nadri $^{1}$ \\ ${ }^{1}$ English Language Department, Chabahar Maritime University, Chabahar, Sistan \& Baluchestan Province, Iran \\ Correspondence: Nahid Yarahmadzehi, English Language Department, Chabahar Maritime University, Chabahar, \\ Sistan \& Baluchestan Province, Iran. E-mail: n.yarahmadzehi@cmu.ac.ir
}

Received: December 29, 2012 Accepted: January 14, 2012 Online Published: January 25, 2013

doi:10.5539/ijel.v3n1p60

URL: http://dx.doi.org/10.5539/ijel.v3n1p60

\begin{abstract}
English phrasal verbs have special semantic and structural features which make their translation into other languages a difficult task. Yet it seems that these linguistic constructions have been neglected by Persian translation theorists and translators. In this study, the first volume - chapters 1 to 12 - of three of the Persian translations of the novel "Harry Potter and the Order of the Phoenix" by Rowling (2005) were examined along the original text on the basis of Newmark (1988) and Vinay and Darblenet's (1995) taxonomies of translation procedures. Through juxtaposition of the English phrasal verbs with their Persian equivalents, the type and the frequency of the applied translation procedures were identified and calculated. The researchers used three criteria of accuracy, clarity and naturalness by Larson (1998) to assess the quality of the applied translation procedures in particular and the translations in general. The results of the study showed that equivalence is the most frequent as well as the most successful translation procedure used in the Persian translations. According to the mean of the scores received for accuracy, clarity and naturalness of the translation procedures, it was also found that the translation by Eslamie (2008) fared better in translating English phrasal verbs into Persian.
\end{abstract}

Keywords: translation procedure, translation quality assessment, accuracy, clarity, naturalness

\section{Introduction}

\subsection{English Phrasal Verbs and Their Translatability into Persian}

English abounds with phrasal verbs and has shown a rapid growth in the production of these linguistic units. Most phrasal verbs (PVs) have several meanings which must be determined within the context. They also possess a number of semantic, syntactic, structural, stylistic, and pragmatic characteristics that might make their translation a difficult task (Hosseini, 2006). Although there are many dictionaries which the translator can consult when translating English phrasal verbs, according to Yatskovitch (1999), the profound comprehension of the phrasal verbs and the way they are translated remains undetected. Furthermore, phrasal verbs belong to Germanic languages and are absent in the Persian language, and according to Baker, "the lack of a grammatical device can make the translation of the entire conceptual information very difficult" (1992, p. 87). The dissimilarity in the form and structure of the two languages (different grammatical structures in the SL and TL) may cause remarkable changes in the way information is carried across. Persian compound verbs, which according to Hosseini (2006) bear the same sense as that of English phrasal verbs and are their translation equivalents, are few, making it difficult for the translator to find an equivalent in Persian while preserving dynamic equivalence. Even when there is a Persian equivalent for the English phrasal verb, the structures are different to the extent that it is difficult to preserve the formal correspondence between the two texts. It is obvious that in this situation the discrepancies between the two languages lead to a great loss in the process of translation.

Given these facts and since there is not ample research done on Persian translations of phrasal verbs, there are enough reasons to justify the investigation of such lexical units in translation. In this study, the first volume chapters 1 to 12 - of three of the Persian translations of the novel "Harry Potter and the Order of the Phoenix" by Rowling (2005) were examined along the original text on the basis of Newmark (1988) and Vinay and Darblenet's (1995) taxonomies of translation procedures. Due to their novelty and the fact that they are used in current English, for example in newspapers and magazines as well as in colloquialism and novels, phrasal verbs are abundantly found in Harry potter series making them an adequate source of data for this study's objectives. 
Given the semantic and syntactic complexity of phrasal verbs and the difficulties they cause in the process of translation, Persian translators might have faced problems in rendering phrasal verbs of "Harry Potter and the Order of the Phoenix" into Persian, and it is useful to look at the procedures they have used while translating so that we would be able to determine the most adequate procedures used for translating phrasal verbs into Persian and to measure the extent to which the translators have been successful in preserving accuracy, clarity, and naturalness in the translation of phrasal verbs.

\subsection{Review of Related Literature}

Despite the importance of phrasal verbs and the difficulties they might produce in teaching English language and also in translating from English into Persian, not much work has been done in the field to accelerate the job of Persian translators and teachers. Yet, researchers from other countries (Yatskovitch (1999), Claridge (2002) Mudraya, et al (2005)) have worked on the issue, i.e. translating English phrasal verbs into different languages; e.g. Russian, French, German, etc. The only existing work on the translation of phrasal verbs into Persian, as far as the researchers are aware, relates to the investigation of translation of phrasal verbs in the novel "the Lord of Flies" by Hosseini (2006). In her study, Hosseini (2006) investigated English phrasal verbs from the point of view of their translation into Persian and examined any possible loss of features originally attached to their uses. She came to the conclusion that most English phrasal verbs are translated into Persian compound verbs, and also that, it was impossible to preserve all semantic, syntactic, stylistic, register and pragmatic properties of phrasal verbs when translating them into Persian. She found that pragmatic meaning was the most difficult feature to be observed and the most probable to get lost in translation. According to Hosseini (2006), Persian translators mostly sacrifice style for meaning, which is the best decision according to Nida (1974, p. 12), who suggested that "whenever a translator cannot keep the stylistic properties of the original text, they had better render just the semantic meaning correctly". Persian translators, in addition, do not preserve the level of informality of the English phrasal verbs, which is their most significant feature. Hosseini (2006) concluded that the Persian translator has to render one or two properties that seem to be more important to the meaning of the whole text, other properties being bound to disappear in the process of translation.

\subsection{Translation Procedures}

Since this study deals with the translation of phrasal verbs, which are considered to be phrases, translation procedures (TPs) are of utmost importance all throughout the work. Many theorists have desired to develop a comprehensive and precise categorization of TPs. In this study, the researchers opted for the taxonomies of TPs provided by Newmark (1988) and Vinay and Darbelnet (1995) as the basis of their work. Since some TPs of each theorist overlap with some TPs proposed by the others; the researchers reduced the number of TPs by removing some overlapping procedures. The TPs to be considered are categorized in table 1 and table 2 .

Table 1. Translation procedures adopted in this study from Newmark's taxonomy (1988)

\begin{tabular}{|c|c|c|c|}
\hline & Newmark's Taxonomy & & \\
\hline 1 & literal translation & 8 & shifts \\
\hline 2 & transference & 9 & modulation \\
\hline 3 & naturalization & 10 & recognized translation \\
\hline 4 & equivalent & 11 & translation label \\
\hline 5 & synonymy & 12 & compensation \\
\hline 6 & through translation & 13 & componential analysis \\
\hline 7 & paraphrase & 14 & couplet \\
\hline 15 & notes, additions, glosses & & \\
\hline
\end{tabular}

Table 2. Translation procedures adopted in this study from Vinay and Darbelnet's taxonomy (1995)

\begin{tabular}{llll}
\hline \multicolumn{4}{c}{ Vinay\& Darbelnet's Taxonomy } \\
\hline 1 & borrowing & 5 & modulation \\
2 & calque & 6 & equivalence \\
3 & literal translation & 7 & adaptation \\
4 & transposition & & \\
\hline
\end{tabular}




\subsection{Translation Quality Assessment}

The field of Translation Assessment is problematic, and it is often difficult to tell the difference between, e.g., translation evaluation, translation criticism, and translation quality assessment. In an attempt to answer the question of why to test the translation, Larson $(1998$, p.529) asserts three main reasons: "The translator wants to be sure his translation is accurate, clear and natural." These are three determining and widely accepted criteria in assessing the quality of any translation. Seeking objectivity in selecting the criteria for assessing the quality of the translations subject to this study, the researchers used Larson's criteria.

An inclusive and nearly exact indicator for the quality category of accuracy to be utilized in this investigation is adapted from Abdullah (1996). He conceives of four levels for accuracy of a translated text:

1. Bad: Semantically misleading and incomprehensible, unclear meaning, there are some grammatical errors, and deviation of meaning.

2. Fair: Correct meaning, with minimum redundancy and grammatical errors.

3. Good: Correct meaning, with no omission, addition or any changes of meaning.

4. Excellent: Accurate and clear meaning, without any omission or changes of meaning.

Larson (1998) argues that, a translation may be accurate but still not communicate to the people for whom it is prepared due to lack of clarity. The quality category of clarity as cited in Abdullah (1996) can be evaluated on four levels:

1. Bad: Stylistically awkward, structurally burdensome and poorly structured, with diction and mechanical errors.

2. Fair: Complex syntax, but understandable meaning, with some diction or mechanical errors.

3. Good: Appropriate words, phrases and grammar and clear meaning.

4. Excellent: Easy to understand, correct words, phrase and grammar, nothing ambiguous.

Eventually, the purpose of naturalness tests is to see if the form of the translation is natural and the style appropriate. Abdullah's indicators (1996) for the quality category of naturalness are the following:

1. Bad: Unnatural form, with awkward language, linguistically unnatural and stylistically awkward.

2. Fair: Make sense with minimum unnatural words, grammar, phrase and idiom.

3. Good: Correct meaning, appropriate idioms and words but there are some syntactic structure errors.

4. Excellent: Make sense, read naturally (written in ordinary language, common grammar, proper idioms and words)

Abdullah's (1996) indicators for assessing the accuracy, clarity and naturalness of translations were adopted by the researchers to assess the quality of the Persian translations subject to this study.

\subsection{Research Questions}

This research set out to answer four major questions:

1. What is the most frequent translation procedure used for translating English phrasal verbs in the novel "Harry Potter and the Order of the Phoenix" into Persian?

2. What are the most successful procedures used for translating English PV in this work based on the three criteria of accuracy, clarity and naturalness?

3. Which translation procedure is the most adequate one for translating English phrasal verbs into Persian according to its frequency and translation quality assessment?

4. Which Persian translation among the three existing translations of the novel "Harry Potter and the Order of the Phoenix" fare better in translating English phrasal verbs according to the findings of the study?

The results of the study might be useful as additional information in teaching translation specially when dealing with PVs. It is possible to embed the findings in the course-books for translation students. The findings of this study can also be used as a reference for translators and help authors willing to compile a comprehensive English-Persian dictionary of PVs - a neglected requisite for the Persian language - or grammar books. Finally, by touching on these topics, the researchers hope to clarify the value of English PVs in translation.

\section{Method and Materials}

In Descriptive Translation Studies, Translation can be approached from three focal points namely, function, 
process or product. This study was concerned with the product of translation and was a comparative analysis of three target texts of the same source text. The main corpus employed in this study was the first volume of "Harry Potter and the Order of the Phoenix" along with the translated versions of the same volume in Persian by Eslamie (2008), Riahipur (2003), Bigdelu (2004). Being a fantasy novel, Harry Potter series takes advantage of a great number of PVs to portray a good image of the wizardry land and produce the sense of excitement in the readers.

The criterion to distinguish PVs was the presence of one of the ten particles about, along, back, down, in, of, on, out, through, up, taken from the alphabetical list of particles and prepositions in Oxford Dictionary of Phrasal Verbs (1993, p. vii). In order for the samples of this research to meet the representativeness criterion, i.e. to be representative of the whole population, the researchers decided to select all the PVs, containing one of the above mentioned particles, present in the first twelve chapters of the first volume of the English novel along their Persian equivalents. These PVs were identified, classified and listed in charts, the TP each translator had used in translating each one of them was outlined by means of tabulations, and the most frequent TP each translator had used was detected. Then the frequencies of TPs used by the three translators were compared. In the next phase of the research, the quality of each translation equivalent was determined in order to assess the value and success of the applied TP. The indicator for the quality categories of accuracy, clarity and naturalness was adapted from Abdullah (1996).The scoring of the translation equivalents was done by the researchers. In this study, the total percentage assigned to all of the three criteria was 100 percent, of which each quality category received 33.33 percent; that is 33.33 scores totaling to 100 points for each translation equivalent. After deciding upon the accuracy, clarity and naturalness of the translation equivalents, the total number of occurrences of each quality category was calculated and then multiplied by the percentage of the score they received, i.e. 33.33 percent for each. The scores for accuracy, clarity and naturalness of every TP were added in the next stage based on which the value of each TP in each single translation or among the three translations was determined. In the last stage of the study, the mean of percentages pertaining to each procedure in all the three translations was calculated to decide upon the score each translation and TP would receive and, hence, to specify its degree of success. The formula to calculate the mean was as follows:

$$
\mathrm{M}_{\mathrm{x}}=\frac{\sum x}{N}
$$

In this equation $\left(\mathrm{M}_{\mathrm{x}}\right)$ is the mean of scores, $\left(\sum x\right)$ is the sum of the scores achieved in accuracy, clarity and naturalness and $(\mathrm{N})$ is the number of scores.

The quality of all TPs was assessed and presented in graphs to see which procedures had been most successful (most accurate, most natural and clearest) in all the three translations. The total number each procedure obtained showed its degree of success and the ultimate score each translation received showed the degree of its success. In the end, the most successful TP according to the graphs was compared to the most frequent TP to see if they matched, i.e. if the most frequent TP was also the most successful one and, hence, the most adequate for the translations of English PVs.

\section{Results and Discussion}

The present study involved an investigation on the translation of English PVs into Persian. The data of the study - the English PVs - were collected and classified with the help of the definitions provided by Quirk et al. (1998). Afterwards, the translation equivalents were gathered from the three translated versions by Eslamie (2008), Riahipur (2003) and Bigdelu (2004) and the TPs applied in the translation of each PV were identified and presented in charts. By doing so the most frequent TP was identified. In Table 3, the frequency of every single procedure in each translation and its total frequency in all of the translations are presented.

Table 3. Frequency of procedures

\begin{tabular}{lccccccccccc}
\hline & $\begin{array}{c}\text { Equiva- } \\
\text { lence }\end{array}$ & couplets & $\begin{array}{c}\text { Expan- } \\
\text { sion }\end{array}$ & literal & shift & modulation & $\begin{array}{c}\text { Para- } \\
\text { phrase }\end{array}$ & $\begin{array}{c}\text { reduction } \\
\text { synonymy }\end{array}$ & $\begin{array}{c}\text { Zero } \\
\text { translation }\end{array}$ & $\begin{array}{c}\text { mis- } \\
\text { translation }\end{array}$ \\
\hline $\begin{array}{l}\text { Translation } \\
\text { No.1 }\end{array}$ & 477 & 93 & 59 & 226 & 138 & 69 & 14 & 199 & 259 \\
$\begin{array}{l}\text { Translation } \\
\text { No.2 }\end{array}$ & 406 & 81 & 27 & 256 & 163 & 54 & 8 & 210 & 231 \\
$\begin{array}{l}\text { Translation } \\
\text { No.3 }\end{array}$ & 361 & 66 & 33 & 286 & 151 & 37 & 11 & 202 & 240 \\
Total & 1244 & 240 & 119 & 768 & 452 & 160 & 33 & 611 & 76 \\
\hline
\end{tabular}


As shown in this table, equivalence was the most frequently used procedure in translation of PVs. It happened 1244 times in all of the translations. All translators used equivalence more than other procedures. Literal translation was used 768 times by the translators, thus occupying the second place. Synonymy takes the third place in this table as it was used 730 times in all of the translations. The next frequent procedure is reduction, which was applied 611 times. The procedure that takes the fifth place is shifts with the total frequency of 452 . Couplets are used 240 times by the translators and a large number - 210 - of PVs were mistranslated in the three translations. 152 of these mistranslations belonged to Bigdelu's (2004) translation. 197 PVs were not translated at all, 160 PVs were translated through modulation, and expansion was used to translate 119 PVs in total. The lowest level of frequency belonged to paraphrase, which was used for only 33 cases in all the three translations.

In the next phase of the research, the total number of occurrences of each quality category - accuracy, clarity, and naturalness - was calculated and multiplied by the percentage of the score they received, i.e. 33.33 percent for each. Then the scores for accuracy, clarity and naturalness of every TP were added. Hence, the value of each TP in any single translation or among the three translations was determined. In this study, the total percentage assigned to all the three criteria was 100 percent of which each category received 33.33 percent. In the last step, the mean of percentages pertaining to each procedure in all the three translations was calculated to decide upon the score each TP would receive. The total score of each procedure shows how much each procedure has been successful according to the three quality categories of accuracy, clarity and naturalness.

Table 4. The value of translation procedures

\begin{tabular}{lcccc}
\hline Translation procedure & Translation No.1 & Translation No. 2 & Translation No. 3 & Total Percentage \\
\hline equivalence & 93.42 & 94.24 & 92.97 & 93.54 \\
couplets & 73.79 & 78.18 & 81.3 & 77.75 \\
expansion & 89.83 & 88.88 & 89.89 & 89.53 \\
literal & 94.38 & 94.13 & 88.45 & 92.32 \\
shift & 63.76 & 59.91 & 51.42 & 58.36 \\
modulation & 83.08 & 79.00 & 72.06 & 78.04 \\
paraphrase & 85.70 & 74.99 & 72.72 & 77.80 \\
reduction & 85.58 & 84.27 & 81.01 & 83.62 \\
synonymy & 87.50 & 85.70 & 53.46 & 75.55 \\
zero translation & 0 & 0 & 0 & 0 \\
mistranslation & 0 & 0 & 0 & 0 \\
\hline
\end{tabular}

Table 4 shows that equivalence has been the most successful procedure in translation of PVs, since it achieved 93.54 score after the evaluation of the procedures. After equivalence, literal translation received the highest score which is 93.42. Though not so much frequent, expansion is in the third place in this table with the frequency of 89.53. The forth most successful TP is reduction, which received 83.62 scores. Modulation and paraphrase each acquired 78.04 and 77.80 scores respectively. With a minor difference to the sixth procedure, couplets, takes the seventh place in this table with the total score of 77.75 scores. Synonymy takes the eighth place with 75.55 scores. Shifts achieved only 58.36 scores while mistranslation and zero translation did not receive any score at all.

By calculating the mean of TPs relating to every translation, the quality of the translations was determined and it was observed that in Eslamie's (2008) translation, PVs are translated better according to the quality categories of accuracy, clarity and naturalness. The mean of the value of the TPs relating to the first translation by Eslamie (2008) was 68.82. The second translation, by Riahipur (2003), achieved 67. 2 scores in this study and was the second successful translation as for PVs. By acquiring 62.11 scores, the third translation, by Bigdelu (2004), remained in the third place regarding the quality of the translations.

The answer to the first question of this research, which sought the most frequent TP applied to English PVs, is equivalence. Equivalence as a TP was used 1244 times in the three translations. It has quite a large discrepancy in amount with the next most frequent procedure which is literal translation and occurred 768 times. Equivalence is also the most frequent TP in all the three translations. Therefore, the answer to the second research question enquiring about the most successful TP is also equivalence. 
The assessment of the translations showed that equivalence achieved the highest score -93.54 percent - whereas literal translation received 92.32 scores which put it in the seconds place. Therefore, as an answer to the third question of the research, it can be stated that equivalence is the most adequate TP for translation of the English PVs into Persian since it was the most frequent TP in translation of the PVs and achieved the highest score in the assessment of the translations quality. These two procedures - equivalence and literal translation - filling the first and second place in translation of PVs, originate from the idiomatic and non-idiomatic quality of PVs. Finally, through the evaluation of all the three translations, it was found that the translation by Vida Eslamieh (2008) fared better in translating the PVs of the novel "Harry Potter and the Order of the Phoenix" into Persian.

\section{Conclusions}

Throughout the course of this study, the researchers found that as a first requirement, the translator must be familiar with the construction of PVs and be able to distinguish idiomatic PVs from non-idiomatic ones. They must pay great attention to the translation of the idiomatic PVs, since the translation of any idiomatic expression calls for a very careful treatment. The translator has to be careful not to inappropriately eliminate the particle. Only when the context provides features of the action denoted by the particle, is the translator entitled to remove the particle. As seen in the analysis of the procedures of expansion and shift, the meaning a particle contributes to the meaning of an English PV might have to be conveyed through a separate verb in Persian. Sometimes, context provides the specific characteristics of the action which is denoted by a certain PV in English and in this way it helps the translator to seek a certain expression which is closest in meaning to the original idea and at the same time meets the lexical, grammatical and cultural requirements of the target language. In cases where context may be of little help, a good explanatory or specialized dictionary of PVs can mostly help the translator.

One problem in translating PVs lies in the fact that it is difficult to use PVs and that translators are not well familiar with or do not feel easy enough to use PVs. One possible reason is that PVs have not been amply placed within the EFL and translation teaching materials to familiarize English language learners and translators with these constructions; therefore, the frequency of PVs within the translation teaching corpuses must be revisited and revised accordingly to reduce the problems of translators, especially those translating from Persian to English, in finding adequate natural verbs which make the target texts sound more natural. Conducting further research on this ground will undoubtedly help reduce problems of this kind. An area which requires further research relates to another semantic feature of PVs; the possibility of preserving the polysemous meaning of English PVs while translating into Persian, especially when it comes to translating literary texts. The researchers are hopeful that this study will encourage other researchers and students working or studying in the area of translation studies, to conduct similar studies on other linguistic constructions and help to prepare a comprehensive corpus which can be used as a reference for translators who translate from English to Persian and vice versa.

\section{References}

Abdullah, A. (1996). Faktor-factor yang Tarkait dengan Terjemehen. PPS Universitas Pendidikan Indonasia.

Al-Zoubi, M. Q. R., \& Al-Hassnawi, A. R. (2001). Constructing a model for shift analysis in translation. Translation Theory. Retrieved on March 10, 2010 from http://accurapid.com/journal/18theory.htm

Baker, M. (1992). In Other Words: A Coursebook on Translation. London: Routledge. http://dx.doi.org/10.4324/9780203327579

Biber, D., Conrad, S., \& Leech, G. (2002). Longman Student Grammar of Spoken and Written English. Essex: Pearson Education Limited.

Bolinger, D. (1971). The Phrasal Verb in English. Cambridge: Harvard University Press.

Catford, J. C. (1965). A Linguistic Theory of Translation. London: Oxford University Press.

Claridge, C. (2002). Translating Phrasal Verbs in language and computers, 42(1). Retrieved on March 21, 2010 from http://www.ingentinaconnect.com/content/rodopi/lang

Cornell, A. (1985). Realistic Goals in Teaching and Learning Phrasal Verbs. IRAL, 23, 269-280. http://dx.doi.org/10.1515/iral.1985.23.1-4.269

Cowie, A. P., \& Mackin, R. (1993). Oxford Dictionary of Phrasal Verbs. Oxford: Oxford University Press.

Crystal, D. (1995). Cambridge Encyclopedia of the English Language. Cambridge/New York, NY: Cambridge University Press.

Darwin, C., \& Gray, L. (1999). Going after the Phrasal Verb: An Alternative Approach to Classification. TESOL 
Quarterly, 33, 65-83. http://dx.doi.org/10.2307/3588191

Dehé, N. (2002). Particle Verbs in English: Syntax, information structure and intonation. Amsterdam/Philadelphia: John Benjamins Publishing Company.

Hannan, P. (1998). Particles and Gravity: Phrasal Verbs with 'Up' and 'Down'. MET, 7, 21-27.

Hoseini, M. (2006). An Investigation of the Translation of English Phrasal Verbs into Persian: The Case of Lord of the Flies and Three Persian Translations (Master's thesis). Isfahan University, Iran.

House, J. (2001). Translation Quality Assessment: Linguistic Description versus Social Evaluation. Mete. Translators' Journal, 46, 243-257.

Hughes, A. (1989). Testing for Language Teachers. Cambridge: Cambridge University Press.

Lamont, G. J. M. (2005). The Historical Rise of the English Phrasal Verb. Retrieved on February 8, 2010 from $\mathrm{http} / / / \mathrm{www} . c h a s s . u t o r o n t o . c a / \sim$ cpercy/courses/6361lamont.html

Larson, M. L. (1984). Meaning-based Translation: A Guide to Cross-language Equivalence. Lanham: University Press of America.

Lederer, R. (1989). Crazy English. The Ultimate Joy Ride Through Our language. New York: Pocket Books

McArthur, T., \& Atkins, B. (1974). Dictionary of English Phrasal Verbs and their Idioms. London and Glasgow: Collins.

Mudraya, O. (2005). English-Russian-Finnish Cross-Language Comparison of Phrasal Verb Translation $\begin{array}{lllll}\text { Equivalents. } & \text { Retrieved } & \text { February } & 15, & 2010\end{array}$ www.comp.lancs.ac.uk/ paul/publications/phraseology05.pdf_

Munday, J. (2001). Introducing Translation Studies: Theories and Applications. New York: Routledge.

Newmark, P. (1988). A Textbook of Translation. United Kingdom: Prentice Hall International.

Nida, E. A. (1964). Towards a Science of Translating. Leiden: E. J. Brill.

Nida, E. A., \& Taber, C. R. (1969/1982). The Theory and Practice of Translation. Leiden: E. J. Brill.

Quirk, R., Greenbaum, S., Leech, G., \& Svartvik, J. (1985). A Comprehensive Grammar of the English Language. London \& New York: Longman.

Rowling, J. K. (2005). Harry Potter and the Order of the Phoenix. Retrieved February 10, 2010 from http://www.brothersoft.com/widgets/harry-potter-and-the-half-blood-prince-download-189317.html

Salami, E. (2009). A Corpus-based Study of Units of Translation in English-Persian Literary Translations. Mofid University, Qom, Iran. Retrieved May 23, 2010 from www.TranslationDirectory.com

Spears, R. A. (1993). NTC's Dictionary of Phrasal Verbs and Other Idiomatic Verbal Phrases. United States of America: NTC (National textbook company) publishing group.

Vinay, J. P., \& Darbelnet, J. (1995). Comparative Stylistics of French and English: A Methodology for Translation (J. C. Sager \& M. J. Hamel, Trans.). Amsterdam/Philadelphia: John Benjamins.

Yatskovitch, I. (1999). Some Ways of Translating English Phrasal Verbs into Russian. Translation Journal, 3(3). Retrieved on March 21, 2010 from http://www.accurapid.com/journal/09russ.htm 